\title{
Detection of HIV Viral Load in Liquid and Dried Plasma Spots Among HIV Infected Patients in Jos University Teaching Hospital, Plateau State, Nigeria
}

\author{
Kahansim Adangmah Barminas ${ }^{1, ~ *, ~ R a m y i l ~ M a m z h i-C r o w n ~ S e l j u l ' 2, ~ I m a d e ~ E . ~ G o d w i n ~}{ }^{3}$, \\ Mu'azu Muhammad Auwal ${ }^{3}$, Agbaji O. Oche ${ }^{3}$, Banwat Edmund ${ }^{4}$ \\ ${ }^{1}$ The Carter Centre Nigeria, Jos, Nigeria \\ ${ }^{2}$ Dept. of Medical Microbiology and Parasitology, College of Medicine and Health Sciences, Faculty of Clinical Sciences, Bingham \\ University, Jos, Nigeria \\ ${ }^{3}$ Department of Infectious Diseases, Aids Prevention Initiative in Nigeria, Jos University Teaching Hospital (APIN-JUTH), Faculty of \\ Medical Sciences, Jos, Nigeria \\ ${ }^{4}$ Department of Medical and Clinical Microbiology, Jos University Teaching Hospital (JUTH), Faculty of Medical Sciences, Jos, Nigeria
}

Email address:

barminaskahansim@yahoo.com (K. A. Barminas)

${ }^{*}$ Corresponding author

\section{To cite this article:}

Kahansim Adangmah Barminas, Ramyil Mamzhi-Crown Seljul, Imade E. Godwin, Mu'azu Muhammad Auwal, Agbaji O. Oche, Banwat Edmund. Detection of HIV Viral Load in Liquid and Dried Plasma Spots Among HIV Infected Patients in Jos University Teaching Hospital, Plateau State, Nigeria. International Journal of HIV/AIDS Prevention, Education and Behavioural Science. Vol. 3, No. 2, 2017, pp. 15-21. doi: 10.11648/j.ijhpebs.20170302.12

Received: March 31, 2017; Accepted: April 14, 2017; Published: May 29, 2017

\begin{abstract}
Despite the remarkable achievement in prevention and control so far attained, HIV incidence is increasing in some countries and regions, Sub-Saharan Africa accounting for $68 \%$ global HIV prevalence with women and young people disproportionately affected. As of 2014 in Nigeria, the HIV prevalence rate among adults ages $15-49$ was 3.17 percent. However, the HIV epidemic in Nigeria is complex and varies widely by region. To compare HIV viral load in liquid and dried plasma on filter paper (whatman 903). A study among HIV patients was carried out in Aids Prevention Initiative (APIN) Centre, Jos University Teaching Hospital, Plateau State, Nigeria to compare viral load in dried plasma spot (DPS) against the liquid plasma (LP) which is the gold standard. 84 adult HIV infected subjects were recruited for this survey with each completed a questionnaire and donated blood for the viral load assay using CobasAmpliprep/TaQmananalyser between September to November 2014. Out of the 84 HIV infected adults, 31\% (26/84) of the subjects were males while the remaining $69 \%$ (58/84) were females. On the other hand, 32 of the patients were treatment experienced, and 52 were treatment naïve. The sensitivities and specificities of dried plasma spots at ambient and refrigeration temperatures were $91.3 \%$ and $100 \%$ respectively $(\mathrm{P}<0.05)$. Viral load was effectively detected in DPS within the log range of 3.0 to $>6.0$. There was a strong positive correlation in this current study between the viral load in LP and DPS as well as LP and DPS-REFR with values of 0.978 and 0.992 respectively as well as mean loss in viral log copies of 0.261 and 0.196 . In general, the result of DPS was highly comparable with that of LP, which suggests that DPS could be used as a valuable alternative in resource constrains settings. This range is useful in providing clinical guidance regarding drug regimen switch in individuals on antiretroviral therapy (ART).
\end{abstract}

Keywords: Dried Plasma Spot (DPS), Liquid Plasma (LP), CobasAmpliprep/TaQmananalyser, Filter Paper (Whatman 903), APIN-JUTH, Nigeria

\section{Introduction}

Global health strategy on HIV/AIDS has been geared towards achieving universal access to HIV prevention, treatment, care and support. Between 2000 - 2010, the number of new HIV infections declined globally by $19 \%$, 
with high burden countries reducing HIV prevalence by more than 25\% among young People aged $15-24$ years [1]. According to NARHS 2012, the current HIV prevalence in the general population is $3.4 \%$ but as of 2014 in Nigeria, the HIV prevalence rate among adults ages 15-49 was 3.17 percent. However, Nigeria has the second-largest number of people living with HIV [2], [29]. The HIV epidemic in Nigeria is complex and varies widely by region. However, Nigeria has been steadfast in its commitments to strengthen its responses to the HIV and AIDS epidemic through the implementation of multi-sectoral comprehensive intervention programs [3]. Antiretroviral therapy access in low and middle income countries increased by 35\% (400,000 in 2003 -5.2 million) in 2009 [7]. Among young people in need in $2010,53 \%$ of pregnant women living with HIV had access to ART to prevent transmission to their unborn infants, increasing by $8 \%$ in 2008. Despite the remarkable achievement in prevention and control so far attained, HIV incidence is increasing in some countries and regions, SubSaharan Africa accounting for $68 \%$ global HIV prevalence with women and young people disproportionately affected. Globally, women in 2009 account for about 52\% (60\% in Sub-Saharan Africa) of adult prevalence [4]. In 2015, It is estimated that a total of 36.7 million people globally are living with HIV/AIDS including 1.8 million children while in the low and middle countries, 19 billion are said to be living with HIV as a result, has negated decade's worth of work on controlling disease, improving nutrition and in many African countries it has become an unprecedented emergency [5] [7]. Simplified approaches to proficiency testing such as the use of control sera like the dried tube test (DTS) developed by the centre for disease control and prevention is encouraged for wider adoption by stakeholders responsible for national level quality assurance [8]. The ability to accurately measure viral RNA in plasma and intracellular compartments of HIV-1 infected people has demonstrated that high level viral replication occurs at all stages of disease. Most poor countries do not have adequate facilities for routine monitoring of laboratory markers of disease activity. Developing countries need field-friendly methods for collection, transportation and accurate measurement of HIV viral load [9].

Accurate measurement of viral RNA in plasma and intracellular compartment of HIV-1 infected persons has enabled dramatic improvement in the understanding of the natural history of the virus and its devastating effects. Studies have convincingly shown that high level viral replication takes place at all stages of the disease and that HIV-1 RNA levels in plasma are predictive of disease outcome, and response to therapy. Although modest progress has been achieved with regards to HIV-1 disease diagnosing and monitoring, some issues still remain largely unsolved if HIV1 quantification is to be used as a routine marker of disease progression and therapeutic efficacy. Limited stability of HIV-1 RNA in liquid plasma and the need for expedient collection, processing and transport of samples on dry ice or liquid nitrogen; although the logistics of specimen handling are being addressed in developing countries, few studies have examined the technical challenges and immediate sample processing and refrigeration are often unavailable. As the developing world bears a disproportion of the global population of people with AIDS and that clinical trials are planned for many of the developing countries, there exists a need to develop a simple and improved sampling methods which can be widely applied under difficult field conditions [10] - [13], [21], [38].

Studies indicate that regardless of the test kit selected, the testing of DPS samples collected on filter paper is an accurate and reliable method for the quantification of viral RNA. Findings indicate complete elution of HIV-1 RNA from filter paper with no measurable loss of nucleic acid during extraction with sensitivity limits of quantification with DPS in the range of approximately $3.0 \log 10 \mathrm{HIV}-1$ RNA copies/ $\mathrm{ml}$, which is the expected value for $50 \mu \mathrm{l}$ sample volumes. Also, rapid disease course for patients with persistent high level viraemia as measured by RNA quantification with both DPS and liquid plasma supports the interpretation that failure to effectively clear virus in the primary stage of infection is associated with rapid clinical progression [14] - [16], [38]. DPS has been used to demonstrate the early detection and quantification of HIV-1 RNA in infected neonates where strong correlation between results obtained using DPS and liquid plasma, with high levels of HIV-1 RNA measured during the first six weeks of life and were persistently high for the first year of life [17], [38]. Dried plasma can be stored for prolonged periods of time at ambient temperature without adversely affecting quantitative HIV-1 RNA determination or changing the categorical result (from positive to negative). Also stable in dried plasma are a growing list of HIV-1 analytes: antibodies, antigens, RNA, and proviral DNA that are unexpectedly stable when dried onto a solid matrix [10], [14], [15], [18] [20]. Athicha et al, 2017 alongside Sally et al., 2015 reported that the ultimate utility of DPS at the global level will depend on the ability of the amplification primers to recognized and amplify different clades with equal efficiency because in their study, the Limit of Detection (LOD) test from the improved DNA extraction method DBS, HIV-1 DNA was $\geq$ 250 copies/ml [21], [38].

The use of liquid plasma for HIV-1 viral load determination and drug resistance genotyping in the rapidly expanding access to ART for HIV patients in low and middle income countries [22], though mobile clinics have made diagnoses conveniently close to patient's homes, there are no standard HIV laboratories near for monitoring of the patient's treatment progress. Transportation cost has been identified as an important barrier to reaching these services [23], [24]. Studies showed that HIV-1 levels in plasma are predictive of disease outcome and response to therapy as well as one of the indicators for drug regiment switching, risk of vertical transmission from seropositive mothers to their babies [25]. In Nigeria 1,449,166 patients were ART eligible in 2011. The growing trend towards the use of rapid tests HIV testing improves likelihood of clients getting access to HIV care and 
prevention services support such as viral load testing. Thus, these findings and the introduction of potent new ARVs stimulated interest in viral load monitoring [26], [27].

The conventional method of viral load assay is via the use of liquid plasma. However, this would pose a serious challenge in developing countries because the facilities and manpower are located in urban areas; thus, samples must be transported on dry ice from remote areas to testing sites, Storage of plasma samples would require freezers which would be costly to maintain and the epileptic power supply is a major challenge in this part of the world. Thus, dryplasma spot (DPS) would provide a suitable alternative to liquid plasma (LP) for HIV viral load due to ease of transportation from clinical sites to testing sites with minimal biohazard risk, ease of storage and requires lesser storage space thus reducing the cost of running the assay.

Aim and Objective: To compare HIV viral load in liquid and dried plasma on filter paper (whatman 903).

\section{Materials and Methods}

\subsection{Study Site and Population}

This study was a comparison between HIV-1 viral load in liquid and dried plasma of adult patients at APIN-JUTH. The study subjects were recruited within a period of 3 Months from September to November 2014. The diagnostic performance assessment was carried out at the Infectious Diseases Unit (IDU) laboratory of the Jos University Teaching Hospital (JUTH) were viral load assay was carried out in this same facility. This facility is an AIDS Prevention Initiative In Nigeria (APIN) programme located in Jos North Local Government Area at $9^{\circ} 55^{\prime} \mathrm{N} 8^{\circ} 54^{\prime} \mathrm{E} / 9.917^{\circ} \mathrm{N} 8.900^{\circ} \mathrm{E}$ of Plateau State, North-central Nigeria. Both sexes were involved in the research work. Blood specimens were collected from all confirmed HIV-1 Positive adult patients attending APIN JUTH clinic to access medical care that have consented and volunteered for the study.Patient's information was collected based on the questionnaire designed.

\subsection{Study Sample Size}

The minimum sample size was obtained from a standard statistical text book [28] for calculating confidence interval in accordance to $3.4 \%$ National prevalence rate [29], but a total of 84 (40\% attrition) paired samples were analyzed at refrigeration and ambient temperatures.

\subsection{Sample collection}

Venous blood samples were collected in vacutainer tubes containing EDTA and centrifuged at $489 \times \mathrm{g}$ for $5 \mathrm{mins}$. Clarified plasma was used to make dried plasma spots (DPS) and the remaining liquid plasma was stored at $-80^{\circ} \mathrm{c}$ prior to evaluation. Dried plasma spots, replicate sets of DPS from a cross section of the patients were prepared by aliquoting 200 microlitres of the liquid plasma using a 100 microlitremicropipettor with plugged tips applied to individual circles of whatman 903 filter paper (one filter paper per patient and has provision for five spots). The filter papers were left to dry in a clean dry protected area free from direct sunlight and dust (laminar flow hood overnight) for four (4) hours. After drying, up to ten DPS cards were inserted into a special sealable plastic bag with desiccants and 84 of the samples were stored at room temperature, while the remaining 84 were kept at refrigeration temperature for 2 weeks before running the assay [30].

\subsection{Laboratory Assay}

The COBAS ${ }^{\circledR}$ AmpliPrep/COBAS ${ }^{\circledR}$ TaqMan ${ }^{\circledR}$ HIV-1 Test, v2.0 permits automated specimen preparation followed by automated reverse transcription, PCR amplification and detection of HIV-1 target RNA and HIV-1 Quantitation Standard (QS) Armored RNA.The processed specimen, containing the magnetic glass particles as well as released HIV-1 RNA and HIV-1 QS RNA, is added to the amplification mixture and transferred to the COBAS $\AA$ TaqMan ${ }^{\circledR}$ Analyzer. The HIV-1 target RNA and the HIV-1 QS RNA are then reverse transcribed, amplified and simultaneously detected by cleavage of two target-specific and one QS-specific dual-labeled oligonucleotide probe [30].

\subsection{Statistical Analysis}

The HIV-1 RNA values were log transformed before analysis for conveniences, with undetectable viral loads and those detectable but below the detection limit of the assay are considered equal to 10. Quantitative variables were expressed as means and compared by student t-test. Log transformed viral load measured in DPS and LP samples were compared by the Pearson correlation analysis. A p value $<0.05$ was considered to be significant. All statistical calculations were performed using SPSS software version 17.0 [30].

\subsection{Ethical Clearance and Confidentiality}

The information obtained in the questionnaire and consent was treated with upmost priority. However, any information that is released did not identify the patient. Approval and clearance for this research was obtained from the Ethical Committee of the Jos University Teaching Hospital (JUTH) as well as APIN management respectively.

\section{Results}

Dried plasma spots (DPS) were available for all the collected liquid plasma (LP) samples $(n=84)$. The paired DPS were kept at ambient and refrigeration temperatures each for a period of two weeks prior to analysis. The coefficients of correlation between the HIV-1 RNA viral loads were calculated by comparing the results of LP to DPS at ambient and LP to DPS at refrigeration temperatures.

The coefficients of correlation of viral loadsfrom LP compared with DPS at ambient temperature and from LP compared with DPS at refrigeration temperature were 0.978 and 0.992 respectively (Pearson correlation test).

In table 1 , the liquid plasma being the conventional 
method shows a sensitivity and specificity of $100 \%$ while dried plasma at ambient and refrigeration temperatures had sensitivities and specificities of $96.4 \%$ and $100 \%$ respectively.

In addition, statistical differences were observed between the mean viral log copies/ml obtained from LP (3.1870), DPS at ambient temperature (2.9260) with mean difference of 0.2610 , and DPS at refrigeration temperature (2.9910) with mean difference of 0.1960 respectively as in tables 2 and 3 .

Table 1. Detectable and non detectable viral load in Liquid Plasma and Dried Plasma spots.

\begin{tabular}{lll}
\hline & Detectable(Positive) & Non - detectable(Negative) \\
\hline VL-LP* & 56 & 28 \\
DPS-AMB** & 54 & 30 \\
DPS-REFR*** & 54 & 30 \\
\hline
\end{tabular}

*Viral load in liquid plasma, $* *$ Dried plasma spots viral load at ambient temperatures, ***Dried plasma viral load at refrigeration temperatures

Table 2. Mean, standard deviations, total number of samples, and correlation coefficient between viral load in liquid plasma and dried plasma.

\begin{tabular}{llll}
\hline & Mean & Number of samples & Standard deviation \\
\hline VL-LP* & 3.187 & 84 & 1.75858 \\
VL-AMB** & 2.926 & 84 & 1.60591 \\
Correlation $=0.978$ & Df $=83$ & & $(\mathrm{p}<0.05)$ \\
\hline
\end{tabular}

*Viral load in liquid plasma, **Dried plasma spots viral load at ambient temperatures.

Table 3. Mean, standard deviations, total number of samples, and correlation coefficient between viral load in liquid plasma and dried plasma.

\begin{tabular}{llll}
\hline & Mean & Number of samples & Standard deviation \\
\hline VL-LP* & 3.187 & 84 & 1.75858 \\
VL-REFR** & 2.991 & 84 & 1.62497 \\
Correlation $=0.992$ & Df $=83$ & & $(\mathrm{p}<0.05)$ \\
\hline
\end{tabular}

*Viral load in liquid plasma, **Dried plasma viral load at refrigeration temperatures

Table 4. Viral load log ranges detected in liquid plasma (LP) and dried plasma spots (DPS).

\begin{tabular}{llll}
\hline VL-LOG RANGES & LP & DPS-AMB & DPS-REFR \\
\hline $1-1.99$ & 31 & 32 & 31 \\
$2-2.99$ & 2 & 4 & 3 \\
$3-3.99$ & 16 & 19 & 17 \\
$4-4.99$ & 22 & 23 & 26 \\
$5-5.99$ & 12 & 6 & 7 \\
$\geq 6.0$ & 1 & 0 & 0 \\
TOTAL & 84 & 84 & 84 \\
\hline
\end{tabular}

Table 5. Summary of results analyzed compared with reported findings.

\begin{tabular}{|c|c|c|c|c|c|}
\hline & Correlation & Sensitivity(\%) & Specificity(\%) & DetectionRate & Mean loss \\
\hline Roche & 0.989 & 98 & 100 & - & - \\
\hline Mbida & $0.916 / 0.92$ & 91 & 100 & - & 0.56 \\
\hline Mauro & - & 91.3 & 100 & - & - \\
\hline Ralph & - & - & - & 3.5 & - \\
\hline Cassol & - & - & - & 3.0 & - \\
\hline Serah & - & - & - & 3.3 & 0.64 \\
\hline Majore & - & - & - & & 0.35 \\
\hline
\end{tabular}

\subsection{Discussion}

The increased access to life-saving antiretroviral drugs has not only raised hope for many people living with HIV in resource-limited countries but also raised challenges for appropriate monitoring. The determination of viral load remains the gold standard by which treatment efficacy is assessed. Besides, viral load has anestablished value in predicting clinical progression to disease, in monitoring response to antiretroviral therapy, and in assessing the risk of vertical transmission by HIV seropositive mothers to newborns as well as monitoring of drug resistance. However, for many areas in the developing world, the prohibitive cost of carrying out viral load is limiting and has mandated the search for suitable alternatives validated against the standard [32].

In this study the p-value was observed to be less than 0.05 which necessitates the rejection of the null hypothesis that says there is no difference between viral load in liquid and in dried plasma (stored at ambient and refrigeration temperatures). The student's t-test was just comparing the means between viral load log copies in liquid and dried plasma. The null hypothesis is thus saying the mean viral 
load log copies in liquid plasma (LP) must be equal to that of the dried plasma (DPS-AMB and DPS-REFR). However the findings of this study showed a sensitivity and specificity of $96.4 \%$ and $100 \%$ respectively for both DPS stored at ambient and refrigeration temperatures. This is consistent with the findings of Mauro et al, 2010 who also reported sensitivity of $91.3 \%$ and specificity of $100 \%$ with $\mathrm{P}<0.05$. The slight difference in the sensitivity observed in both studies could be that they used manual extraction and automated amplification/detection [33]. Also, Mbida et al, (2009) observed $91 \%$ sensitivity and a specificity of $100 \%$ using DPS stored at room temperature for 2 weeks with manual extraction and automated amplification/detection [34].

There was a strong positive correlation in this study between viral load in LP and DPS-AMB as well as LP and DPS-REFR (0.978 and 0.992 respectively, $\mathrm{P}<0.05)$. This is comparable to the works of [34], [32] who reported strong positive correlations of 0.92 and 0.916 respectively. This slight variation could be due to differences in the methodology. This study revealed a stronger correlation in DPS-REFR when compared with DPS-AMB which could be as a result of lesser degradation of viral load in DPSREFR as compared with DPS-AMB. However, in general the result of DPS is highly comparable with that of LP with mean loss in viral load log copies/ml for DPS-AMB and DPS-REFR as 0.261 and 0.196 respectively. Mbidaet al 2009 reported mean losses in viral load log copies/ml of 0.58 similar findings were also reported byMajore et al 2010 and Sarah et al 2010 as 0.35 , and 0.64 respectively $\mathrm{P}<0.05$ [34] - [36].

This study also revealed that DPS can effectively detect viral load within the range of $\log 3.0$ to $\log >6.0$ (Table 4) which is significant in making clinical decisions. This finding is comparable to the work of Ralph et al (2010) who reported a high detection rate at $\log 3.5$ and is useful in providing clinical guidance regarding drug regimen switch in individuals on antiretroviral therapy (ART) [37]. Minimum detection rates of $\operatorname{logs} 3.0$ and 3.3 respectively have also been reported by Mauro et al (2009), and Cassol et al (1997) [33], [16].

\subsection{Conclusion}

The findings of this research showed that the detection of viral load from liquid plasma remains a more robust option due to possible degradation in Dried Plasma Spots. However, DPS can be used as a valuable alternative in detection of viral load in resource constrained settings where the availability of power and other necessary resources may be unavailable. The results obtained from this study may also indicate that HIV-1 viral load determination for resistance genotyping from DPS may also be feasible in resource limited areas.

The study indicates that plasma samples could be collected in areas with limited infrastructures, dried and stored at ambient temperature to be transported to the testing sites which are urban areas that have the equipments and trained personnel to run the assay especially for management of HIV infected patients in resource constrained settings. This could reduce the cost of transportation since so many samples could be collected before transporting to the testing sites. Also, there would be no need of acquiring freezers which add up to the cost and electricity which is a major challenge, minimal biohazard risk, ease of transportation as well as reduced storage space.

\subsection{Contribution to Knowledge and Public Health Practice}

This study adds to a steadily accumulating body of scientific evidence for the use of DPS in place of Liquid plasma where the conditions of testing assays may not be readily available.This also provides useful baseline information for research opportunities in resource limited areas and fast track HIV treatment targets for infected individuals to accurately diagnose HIV and prompt initiation of lifesaving ART, clinical follow-up to ensure sustained viral suppression.

\subsection{Recommendations}

Future research should be focused on the possibility of using whole blood spotted on filter paper instead of plasma as this would eliminate the need for venous blood collection and centrifugation thus, saving cost.The effects of elution time may need to be looked into and the need to increase the diameter of the filter paper to accommodate more sample volume cannot be over emphasized.

\section{Acknowledgement}

Worthy of mention the researchers registered their profound gratitude to APIN JUTH management for sponsoring the project and the use of their state of the art laboratory.

Sincere appreciation goes to Rosemary Pwol, Marc Terve, David Adeniyi and other staff for their assistance during the experimental stage and specimen processes as well as Mrs Eunice Tenite Barminas, Abishai and Adino for their support.

A special thanks to all HIV infected patients who agreed to participate in this research.

\section{References}

[1] UNAIDS: UNAIDs world AIDS day report, 2011.

[2] NHEIA: National HIV/AIDS epidemiology and impact analysis report, 2014.

[3] National population commission (NPC) [Nig] and ICP International; Nig Demographic and Health Survey 2013. Abuja, Nig, and Rockville, Maryland, USA: NPC and ICP international, 2014.

[4] Global network of people living with HIV: Positive health, dignity and prevention. Technical consultationreport 27-28 April, 2009, Hammamet, Tunisia. Amsterdam, the global network of people living with AIDS, 2009. 
[5] RamnikSood:Haematology for students and practitioners. Jaypeebrothers medical publishers ltd. 491-525, 2010.

[6] UNAIDS, 'The Gap Report', 2014.

[7] UNAIDS,'Fact Sheet 2016' UNAIDS, 2016.

[8] WHO, "Expert meeting on short-term HIV diagnosis, treatment initiation and monitoring technologies and approaches". Geneva, Switzerland. 13-14 October, 2011.

[9] Tucker T, Yeats J, "laboratory monitoring of HIV after access to antiretroviral drugs, the next challenge for the developing worlds". Afr Med J; vol.91: 2001, 615.

[10] Behets, F, M. Kashamuka, M. Pappaioanou, T.A. Green, R.W. Ryder, V. Batter, J.R. George, W.H. Hannon, and T.C. Quine, "Stability of human immunodeficiency virus type 1 antibodies in whole blood dried on filter paper and stored under various tropical conditions in Kinshasa, Zaire". $J$. Clin. Microbial. 30: 1992, 1179-1182.

[11] Cassol, S. T. Salas, M. Arella, P. Neumann, M.T. Schechter, and M. O'Shaughnessy, "Use of dried blood spot specimens in the detection of human immunodeficiency virus type 1 by the polymerase chain reaction". J. Clin. Microbial. 29:1991, 667-671.

[12] Katzenstein, D.A, and M. Holodniy, "HIV viral load quantification, HIV resistance and antiretroviral therapy. AIDS clin. Rev. 96: 1995, 277-303.

[13] Mellors, J.W, L.A. Kingsley, C.R. Rinaldo, J.A. Todd, B.S. Hoo, R.P. Kokka, and P. Gupta,"Quantification of HIV-1 RNA in plasma predicts outcome after seroconversion". Ann. Intern. Med. 122: 1995, 573-579.

[14] Mwaba P, Cassol S, Nuun A, et al,. "Whole blood versus plasma spots for measurement of HIV-1 viral load in HIV infected African patients". Lancet; 362: 2003, 2067-2068.

[15] Amellal B, Katlama C, Calvez V, "Evaluation of the use of dried spots and of different storage conditions of plasma for HIV-1 RNA quantification". HIV Med. J; 8: 2007, 396-400.

[16] Cassol S, Gill MJ, Pilon R, et al. "Quantification of Human immunodeficiency type-1 RNA from dried plasma spots collected on filter paper". J ClinMicrobiol; 35: 1997, 27952801.

[17] Lloyd J, Michelle Z, Rodrigo C, Ricardo S, Denise F, Lilian A, "Comparative effectiveness of dried plasma HIV-1 viral load testing in Brazil using ViveST for sample collection". Journal of clinical virology, Vol. 49(4): 2009, 245 - 248.

[18] Knuchel MC, Tomasik Z, Speck RF, Luthy R, Schupbach $\mathrm{J}$,“Ultrasentitive quantitative HIV-1 p24 antigen assay adapted to dried plasma spots to improve treatment monitoring in low resource settings". J ClinVirol; 36: 2006, 64-67.

[19] Stevens G, Rekhviashvili N, Scott LE, Gomin R, Stevens W, "Evaluation of two commercially available, inexpensive alternative assays used for assessing viral load in a cohort of HIV-1 serotype- c infected patients from south Africa". $J$ ClinVirol; 2006, 36: 64-67.

[20] Cassol SA, Lapoite N, Salas T et al "Diagnosis of HIV-1 vertical transmission using the polymerase chain reaction and dried blood spots specimens". J Acquir immune deficsydr; 5: 1992, 113-119.

[21] AthichaMahayotha, WatjanaChangthong, RassameAomsin,
KantanakonPoiyim, "Evaluating the HIV-1 Proviral DNA Detection by Use of Real Time PCR from Blood Samples and Dried Blood Spots". American Journal of Laboratory Medicine. Vol. 2, No. 1, 2017, pp. 7-12. doi: 10.11648/j.ajlm.20170201.12.

[22] Ralph L. Hamers, Pieter W Smit, Wendy Stevens, Rob Schuurman and Tobias F Rinke de Wit, "Dried fluid spots for HIV type-1 viral load and resistance genotyping: a systematic review". International medical press 2009, 1359-6535.

[23] Zachariah R, Harries AD, Manzi M, Gomani P, teck R, Phillips M, Firmenrich P., "Acceptance of anti-retroviral therapy among patients infected with HIV and tuberculosis in rural Malawi is low and associated with cost of transport". PLo S One.121. Doc 2009.

[24] Hardon AP, Akunt D, Comoro C, Ekezie C, Irunde HF, Gerrits T, Kglatwane J, Oyyoba T, Temu F, Laing R. hunger, "Waiting time and transport cost: time to confront challenges to ART adherence in Africa". AIDS care. Vol; 19: 2007, 658-665.

[25] Tarantola, D, "Reducing HIV/AIDS risk, impact and vulnerability”. Bulletin of the world health organization, 20012.

[26] NACA, 'Nigeria GARPR 2015'.

[27] NACAFederal republic of Nigeria. Global AIDS response: Progress report 2012. January, 2011 to December, 2011 reporting period.

[28] Daniel WW, "Biostatistics: A foundation for analysis in the health sciences" 1999.

[29] NARHS, "National HIV/AIDS Reproductive Health Survey", 2012.

[30] COBAS Ampliprep/ Taqman HIV-1 quick reference card/test kits insert.

[31] IBM SPSS Statistics Processor version 20 License authorization wizard. Ink.

[32] Workensh A, Rob S, Tsehaynesh M, Wendelien D, Yohannes M, Jaap G, William A, Michel P, Georgios P, "Use of dried blood spots of whole blood, plasma, and mother's milk collected on filter paper for measurement of HIV-1 burden". Journal of clinical microbiology vol. 10: 2006, 891-896.

[33] Mauro A, Maria P, Giovanni G, Susana C, Giovanna P, Paola G, Richard L, David C, Maria C, Stefano V, Leonardo P, Marina G, "Correlation between HIV-1 viral load quantification in plasma, dried blood spot, and dried plasma spot using Roche Cobas assay". Journal of clinical virology 47: 2010, 4-7.

[34] Mbida AD, Sosso S, Flori P, Saoudin H, Lawrence P, Monnylobe P, Oyono Y, Ndzi E, Cappelli G, Lucht F, Pozzetto B, Oukem-Boyer OO, Bourlet T, "Measure of viral load by using the Abbott Real-Time HIV-1 assay on dried blood and plasma spots specimens collected in two rural dispensaries in Cameroon". Journal of aquire immune DeficSyndr 15(1): 2009, 9-16.

[35] MajoreMonleau, C. Mortaron, C. Laurent, M. Segandy, B. Montes, E. Delaporte, F. Boillot, and M. Peeters, "Evaluation of different RNA extraction methods and storage conditions of dried plasma or blood spots for human immunodeficiency virus type-1 RNA quantification and PCR amplification for drug resistance testing". J Clin. Microbiol. April; 47(4): 2010, 1107-1118. 
[36] Sarah M, Anne B, Caroline C, Anangisye I, Sally E, Ben A, David J, Lorenz V, Werner S, Wendy S, John A, John C, "Evaluation of a dried blood spot HIV-1 RNA program for early infant diagnosis and viral load monitoring at rural and remote health care facilities". AIDS 2010 23(18): 2010, 2459 -2466 .

[37] Raph L. Hamers, Pieter W Smit, Wendy Stevens, Rob Schuurman and Tobias F Rinke de Wit, "Dried fluid spots for
HIV type-1 viral load and resistance genotyping: a systematic review". International medical press: 2010, 13596535 .

[38] Sally MM, Robin LW, Sujit RJ, Douglas HY, Diana H, David MK, "A simple and rapid DNA extraction method from whole blood for highly sensitive detection and quantitation of HIV-1 proviral DNA by real-time PCR". Journal of Viral Methods: 214: 2015, 37-42. 